\title{
An Investigation of Tenascin-C Levels in Rheumatic Mitral Stenosis and Their Response to Percutaneous Mitral Balloon Valvuloplasty
}

\author{
Ahmet Celik $^{a}$ Ozgur Gunebakmaz ${ }^{b}$ Oguzhan Baran ${ }^{c}$ Orhan Dogdu ${ }^{c}$ \\ Deniz Elcik ${ }^{c}$ Mehmet Ali Kobat ${ }^{a}$ Mehmet Balin ${ }^{a}$ Kenan Erdem ${ }^{a}$ \\ Suleyman Aydin ${ }^{d}$ Ibrahim Ozdogruc ${ }^{c}$ Ramazan Topsakal ${ }^{c}$ \\ ${ }^{a}$ Department of Cardiology, Elazig Education and Research Hospital, Elazig, ${ }^{b}$ Department of Cardiology, Dunya \\ Hospital, and ' Department of Cardiology, Erciyes University Medical Faculty, Kayseri, and ${ }^{\mathrm{d}}$ Department of \\ Biochemistry, Firat University Medical Faculty, Elazig, Turkey
}

\section{Key Words}

Tenascin- $C \cdot$ Mitral stenosis $\cdot$ Percutaneous mitral balloon valvuloplasty $\cdot$ Pulmonary hypertension

\begin{abstract}
Objective: The purpose of this study was to evaluate the tenascin-C levels in severe rheumatic mitral stenosis before and after percutaneous mitral balloon valvuloplasty (PMBV).

Subjects and Methods: Forty patients with severe mitral stenosis requiring PMBV and 20 age-matched healthy subjects were included in the study. The mitral valve areas, mitral gradients and systolic pulmonary artery pressure (SPAP) were measured by echocardiography. The SPAP values and mitral gradients were also measured by catheterization before and after PMBV. The blood tenascin-C levels were measured before PMBV and 1 month after the procedure. Results: The echocardiographic mean mitral gradients had a significant decrease after PMBV $(11.7 \pm 2.8$ vs. $5.6 \pm 1.7 \mathrm{~mm} \mathrm{Hg} ; \mathrm{p}<$ $0.001)$ and also those of catheterization (13.9 \pm 4.4 vs. $4.0 \pm$ $2.4 \mathrm{~mm} \mathrm{Hg} ; \mathrm{p}<0.001)$. Mitral valve areas increased significantly after PMBV (from $1.1 \pm 0.1$ to $1.8 \pm 0.2 \mathrm{~cm}^{2}, \mathrm{p}<0.001$ ). Tenascin-C levels decreased significantly in patients after PMBV (from $15.0 \pm 3.8$ to $10.9 \pm 3.1 \mathrm{ng} / \mathrm{ml} ; \mathrm{p}<0.001$ ). Tenascin-C levels were higher in patients with mitral stenosis be-
\end{abstract}

\section{KARGER}

Fax +4161306 1234

E-Mail karger@karger.ch

www.karger.com
(C) 2012 S. Karger AG, Basel

$1011-7571 / 13 / 0221-0029 \$ 38.00 / 0$

Accessible online at:

www.karger.com/mpp fore PMBV than in healthy subjects $(15.0 \pm 3.8$ and $9.4 \pm$ $2.9 \mathrm{ng} / \mathrm{ml} ; \mathrm{p}<0.001$, respectively). There were no significant differences between patients with mitral stenosis after PMBV and healthy subjects $(10.9 \pm 3.1$ and $9.4 \pm 2.9 \mathrm{ng} / \mathrm{ml} ; \mathrm{p}=$ 0.09 , respectively). There was a significant positive correlation between tenascin- $C$ levels and SPAP $(r=0.508, p<$ 0.001 ). In multivariant analysis, tenascin- $C$ predicted mitral stenosis ( $p=0.004$, OR: 2.31). Conclusions: Tenascin- $C$ was an independent predictor for rheumatic mitral stenosis.

Copyright $\odot 2012$ S. Karger AG, Basel

\section{Introduction}

Although the prevalence of rheumatic fever is very low in developed countries, rheumatic mitral stenosis is still an important cardiac disease in undeveloped and developing countries [1]. Patients with severe mitral stenosis still have significant morbidity and mortality rates. The treatment of mitral stenosis by either surgery or percutaneous mitral balloon valvuloplasty (PMBV) improves mitral valve area and as a result improves morbidity and mortality rates [2].

Tenascin-C (TN-C) is an extracellular matrix glycoprotein and is associated with some cardiovascular dis- 
eases such as myocardial infarction [3], severity of heart failure [4], and acute pulmonary thromboembolism [5]. The progression and severity of pulmonary hypertension has also been associated with the production of extracellular matrix components such as TN-C [6]. Smooth muscle cell proliferation is one of the pathophysiologic roles of TN-C in pulmonary hypertension $[7,8]$. TN-C has a role in the pathophysiology of calcified aortic stenosis [9]. Increased levels of $\mathrm{TN}-\mathrm{C}$ have been found in rheumatic aortic valves [10], but there are no data on the TN-C levels in rheumatic mitral valves.

Mitral stenosis is a progressive disease, characterized by hemodynamic abnormalities as well as a rheumatic process $[11,12]$, causing progressive obstruction of left ventricular inflow. When the valve area decreases to $<2 \mathrm{~cm}^{2}$, subjects usually develop exertional dyspnea as an initial symptom. Once this area falls to below $1.5 \mathrm{~cm}^{2}$, intervention is often necessary because of the intolerable symptoms, arrhythmia or pulmonary hypertension, especially in patients with a valve morphology suitable for PMBV.

Fibrotic changes in the heart and lung tissue are controlled by the activity of proteolytic enzymes, such as extracellular matrix-degrading metalloproteinases [13]. Matrix metalloproteinases can stimulate the secretion of $\mathrm{TN}-\mathrm{C}$, which acts as a strong mitogenic cofactor, leading to smooth muscle cell proliferation [14].

Previously it was shown that TN-C was associated with calcific aortic stenosis and rheumatic aortic valves $[9,10]$. The presence of TN-C in heart valves differed under physiological and pathological conditions. In normal valves, TN-C was mainly distributed on the basement membrane under the endothelial cells, whereas no such expression but rather immunoreactivity was found in the deeper layers of the valves in stenotic valves [10]. Additionally, the role of TN-C in physiological mineralization is thought to involve cytokine activation and calcium binding. Previous studies investigated cuspal calcific deposits associated with mineralization of devitalized cells and subcellular vesicles, as well as the deposition of extracellular matrix proteins commonly present in bone. A number of extracellular matrix proteins normally found in bone, including osteocalcin matrix Gla protein, bone morphogenetic protein, matrix metalloproteinase, are present in cardiovascular calcifications, including calcified valves [9]. TN-C is an extracellular matrix glycoprotein that is up-regulated during both development and pathological tissue remodeling. Compelling evidence indicates that TN-C actively participates in normal mineralization. Furthermore, developmental co-localization studies demonstrated that $\mathrm{TN}-\mathrm{C}$ is transiently expressed in heart valves $[9,10]$.

Therefore, the aim of this study was to analyze the blood levels of TN-C in severe rheumatic mitral stenosis and also to assess the impact of PMBV on blood TN-C levels.

\section{Subjects and Methods}

Forty consecutive patients with rheumatic mitral stenosis (mitral stenosis group) who required PMBV and 20 age- and sexmatched healthy volunteers (healthy group) were included in the study. Patients with moderate or severe mitral regurgitation, any moderate or severe valvular heart disease except mitral stenosis, history of coronary artery disease, heart failure, pulmonary embolism, congenital heart disease and chronic kidney disease were excluded from the study. PMBV was performed in all patients. All patients were informed about the study, and written consent was obtained. The study was approved by the institution's Ethics Committee and performed in accordance with the Declaration of Helsinki.

\section{Echocardiography}

Echocardiography was carried out by a cardiology specialist (O.B.) in the Echocardiography Laboratory before and 1 month after PMBV. Echocardiography was performed using Vivid 7 instruments (GE Medical Systems, Milwaukee, Wisc., USA), with a 2.5-MHz transducer and harmonic imaging. According to the recommendations of the American Society of Echocardiography [15], all echocardiographic examinations were performed with the patient lying in the left lateral decubitus position, and twodimensional images were recorded and measured at the apical 4 chambers, 2 chambers, parasternal long and short axis views. Mitral valve areas were calculated using the planimetric method. Diastolic transmitral gradients were measured by continuouswave Doppler echocardiography. Systolic pulmonary artery pressure (sPAP) was measured with continuous-wave Doppler. Tricuspid regurgitation velocity $(\mathrm{V})$ was recorded from any view and used to determine $\mathrm{SPAP}$ ( $\mathrm{PPAP}=4 \mathrm{~V}^{2}+$ right atrial pressure). $\mathrm{V}$ is the maximum velocity of the tricuspid valve regurgitant jet, measured by continuous wave Doppler, added to the estimated right atrial pressure. Right atrial pressure was calculated using the caval respiratory index as described by Kircher et al. [16]. Transesophageal echocardiography was performed in all patients before PMBV.

\section{Catheterization and Valvuloplasty}

Cardiac catheterization was performed using Philips Integris 5000 equipment (Philips Medical Systems, Best, The Netherlands); sPAPs and mitral gradients were also measured with cardiac catheterization. Percutaneous balloon mitral valvuloplasties were performed by two experienced cardiologists (R.T., I.O.), using the Inoue balloon technique. Left ventriculography was performed before and after PMBV to evaluate mitral regurgitation. A successful PBMV was defined as an uncomplicated procedure yielding either a final mitral valve area $>1.5 \mathrm{~cm}^{2}$ and post-valvuloplasty mitral regurgitation $<3+$. 
Table 1. Clinical and demographic characteristics of study subjects

\begin{tabular}{lccl}
\hline & $\begin{array}{c}\text { Mitral stenosis } \\
\text { group }(\mathrm{n}=40)\end{array}$ & $\begin{array}{l}\text { Healthy group } \\
(\mathrm{n}=20)\end{array}$ & $\mathrm{p}$ value \\
\hline Age, years & $44 \pm 11$ & $40 \pm 10$ & 0.1 \\
Female & $30(75)$ & $13(65)$ & 0.3 \\
Hemoglobin, mg/dl & $13.6 \pm 1.7$ & $14 \pm 1.6$ & 0.3 \\
LDL-C, mg/dl & $112 \pm 31$ & $116 \pm 41$ & 0.6 \\
HDL-C, mg/dl & $37 \pm 11$ & $41 \pm 8$ & 0.1 \\
Total-C, mg/dl & $175 \pm 41$ & $185 \pm 58$ & 0.4 \\
Triglyceride, mg/dl & $137 \pm 94$ & $135 \pm 90$ & 0.9 \\
Creatinine, mg/dl & $0.9 \pm 0.1$ & $0.8 \pm 0.1$ & 0.2 \\
History of & & & \\
$\quad$ diabetes mellitus & $2(5)$ & $0(0)$ & 0.4 \\
$\quad$ hypertension & $6(15)$ & $3(15)$ & 0.6 \\
$\quad$ smoke & $6(15)$ & $5(25)$ & 0.2 \\
\hline
\end{tabular}

Values denote means \pm SD or numbers with percentages in parentheses.

LDL-C = Low-density lipoprotein cholesterol; HDL-C = highdensity lipoprotein cholesterol; Total- $\mathrm{C}=$ total cholesterol.

\section{Biochemical Analysis}

Blood samples for TN-C were obtained before and 1 month after PMBV in the mitral stenosis group and obtained once in the control group. The blood samples for TN-C (ELISA kit for Human Tenascin, Uscn Life Science Inc.) were obtained and centrifuged, then stored at $-70^{\circ} \mathrm{C}$ until analysis in all study subjects. Serum $\mathrm{TN}-\mathrm{C}$ levels were measured with the large subunit containing the $\mathrm{C}$ dominant of FN III repeats level using one-step sandwich enzyme immunoassay kits.

\section{Statistical Analysis}

Continuous variables were given as mean \pm SD; categorical variables were defined as percentages and compared with the $\chi^{2}$ test. A value of $\mathrm{p}<0.05$ was considered to be significant. To compare the measurements before and after PMBV, a Student paired test was used. An independent-samples t test was used to compare the data including blood TN-C levels between patients with mitral stenosis and controls. Correlation analyses were performed using the Pearson coefficient of correlation. Multivariable logistic regression analysis was performed to identify the independent predictors of mitral stenosis. The SPSS 15.0 version software was used for basic statistical analysis (version 15, SPSS Inc., Chicago, Ill., USA).

\section{Results}

The baseline clinical and demographic properties of study subjects are shown in table 1 . Of the 40 patients in the mitral stenosis group $30(75 \%)$ and $13(65 \%)$ of 20 in the control group were female. The mean ages of subjects
Table 2. Echocardiographic and catheterization data (means \pm $\mathrm{SD}$ ) of mitral stenosis patients before and after PMBV

\begin{tabular}{lcrl}
\hline & $\begin{array}{l}\text { Before } \\
\text { PMBV }\end{array}$ & $\begin{array}{l}\text { One month } \\
\text { after PMBV }\end{array}$ & value \\
\hline $\begin{array}{l}\text { Echocardiographic data } \\
\text { Mitral valve area, } \mathrm{cm}^{2}\end{array}$ & $1.1 \pm 0.1$ & $1.8 \pm 0.2$ & $<0.001$ \\
Mean gradient, $\mathrm{mm} \mathrm{Hg}$ & $11.7 \pm 2.8$ & $5.6 \pm 1.7$ & $<0.001$ \\
sPAP, mm Hg & $50.8 \pm 13.4$ & $37.3 \pm 8.5$ & $<0.001$ \\
Catheterization data & $13.9 \pm 4.4$ & $4 \pm 2.4$ & $<0.001$ \\
Mean gradient, mm Hg & $52.1 \pm 12.6$ & $38.8 \pm 8.6$ & $<0.001$ \\
sPAP, mm Hg & & & \\
\hline \multicolumn{2}{l}{ a Data were detected before and 1 month after PMBV. } \\
\hline
\end{tabular}

Table 3. Predictors of mitral stenosis by logistic regression analysis

\begin{tabular}{lll}
\hline & \multicolumn{2}{l}{ Multivariable analysis } \\
\cline { 2 - 3 } & OR $(95 \% \mathrm{CI})$ & $\mathrm{p}$ \\
\hline Age & $1.04(0.98-1.10)$ & 0.17 \\
Gender & $0.84(0.28-3.03)$ & 0.78 \\
Diabetes mellitus & $0.98(0.76-1.42)$ & 0.65 \\
Hypertension & $0.71(0.54-1.94)$ & 0.33 \\
Smoking & $0.61(0.38-2.66)$ & 0.49 \\
Total cholesterol & $0.99(0.98-1.01)$ & 0.69 \\
Hemoglobin & $0.70(0.46-1.08)$ & 0.11 \\
Creatinine & $0.82(0.57-1.31)$ & 0.26 \\
TN-C & $2.31(1.31-4.07)$ & 0.004 \\
\hline
\end{tabular}

in the study and control groups were similar ( $44 \pm 11$ vs. $40 \pm 10$ years). All patients had successful PMBV. Before PMBV, the patients were mean New York Heart Association Class (NYHA) $2.2 \pm 0.5$ symptomatic (33 were NYHA class II, 6 NYHA class III and 1 was NYHA class IV). Eight of 40 patients with mitral stenosis had atrial fibrillation. None of the patients had thrombi in the left atrium and left atrial appendage before PMBV. The left ventricular systolic, diastolic diameters and ejection fractions were similar before and after PMBV. In left ventriculography, there were no cases of severe mitral regurgitation in mitral stenosis patients after PMBV.

As shown in table 2, the mean mitral gradients on both echocardiography and catheterization showed a significant decrease after PMBV $(11.7 \pm 2.8$ to $5.6 \pm 1.7 \mathrm{~mm}$ Hg; $p<0.001$ on echocardiography and $13.9 \pm 4.4$ to 4.0 


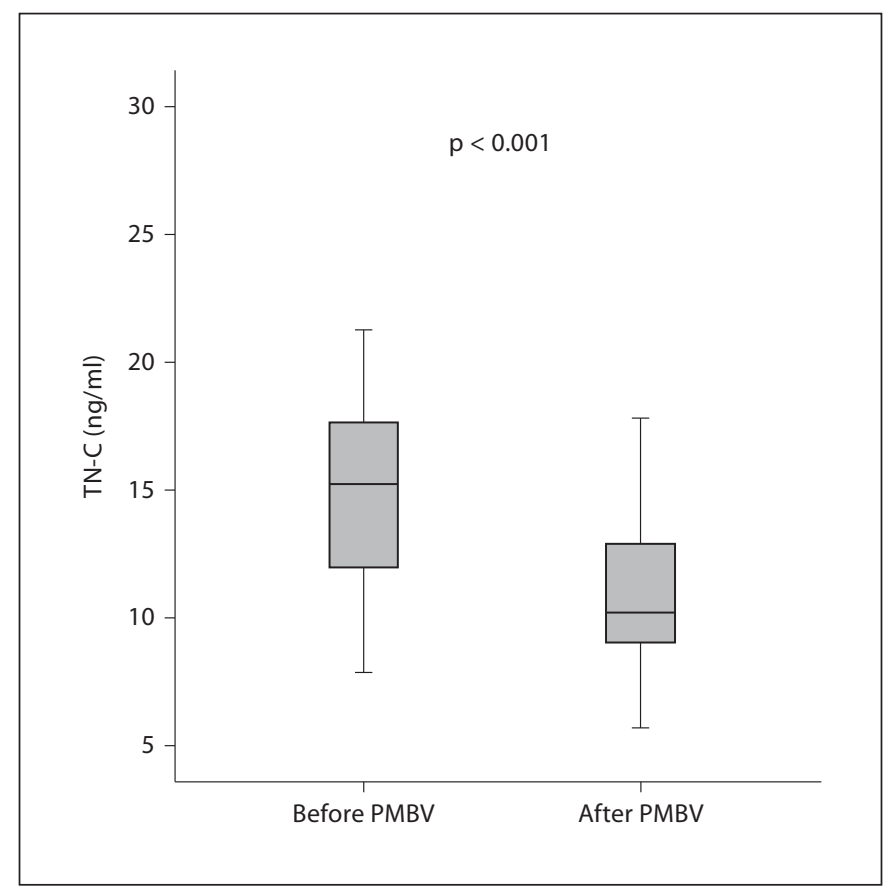

Fig. 1. Analysis of TN-C levels in mitral stenosis patients (before and 1 month after PMBV) and healthy subjects. Mean TN-C levels were $9.4 \pm 2.9 \mathrm{ng} / \mathrm{ml}$ in healthy controls, $15.0 \pm 3.8 \mathrm{ng} / \mathrm{ml}$ in mitral stenosis patients before PMBV and $10.9 \pm 3.1 \mathrm{ng} / \mathrm{ml}$ in mitral stenosis patients 1 month after PMBV.

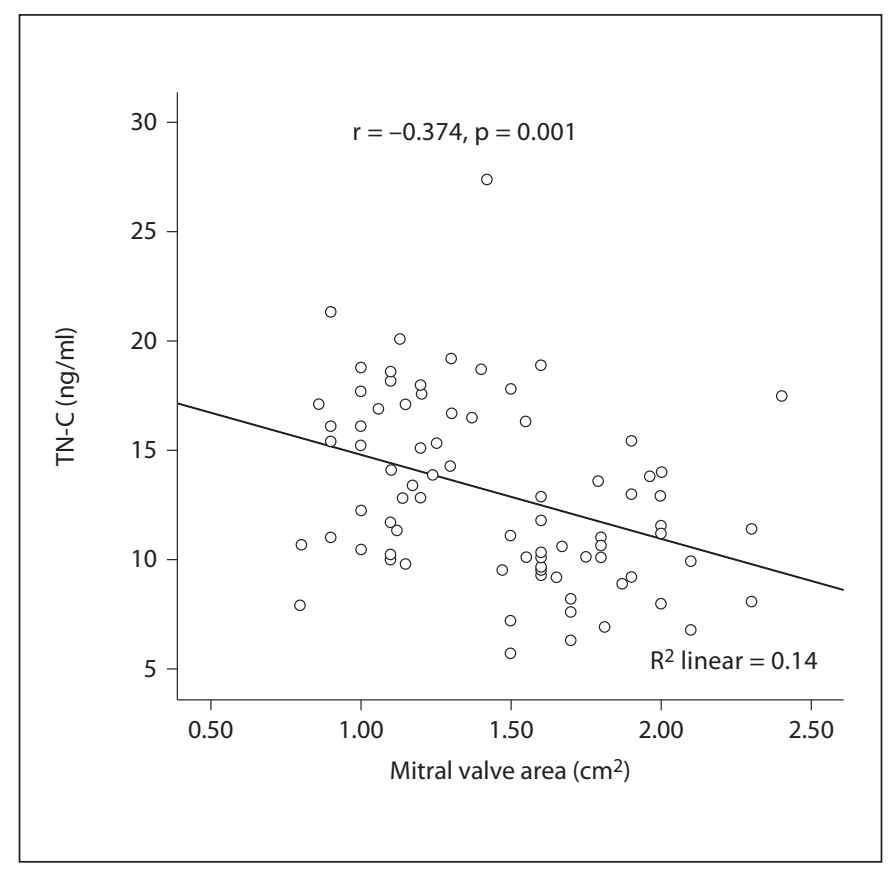

Fig. 3. Negative correlation between mitral valve area and TN-C levels.

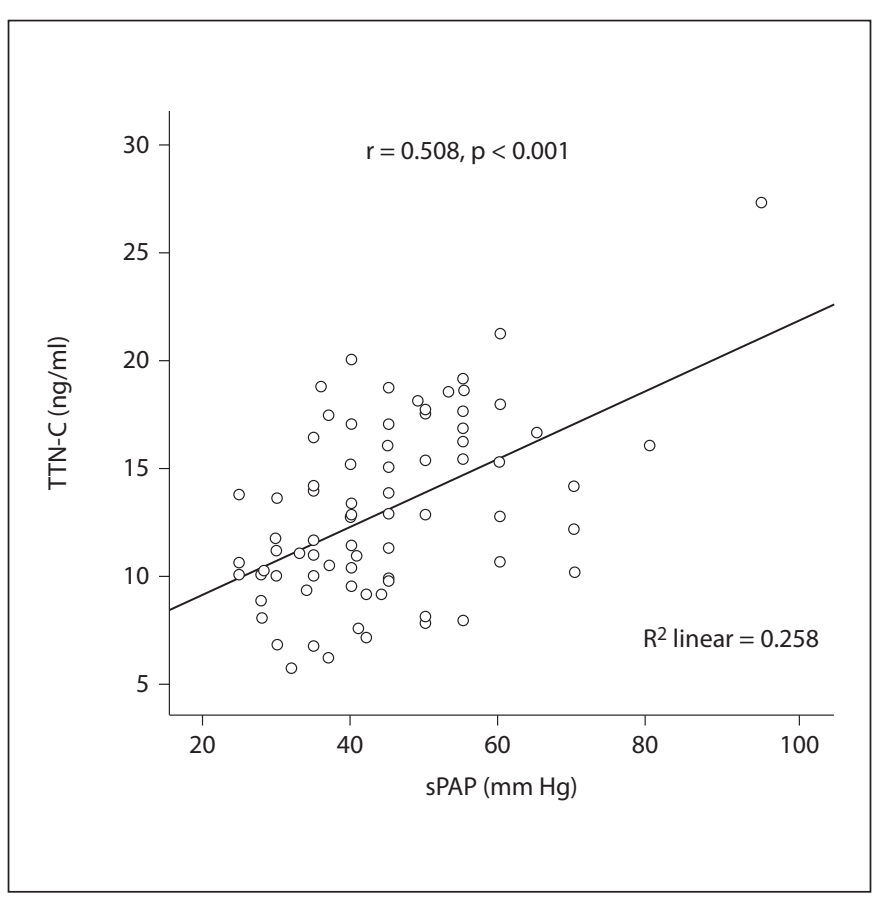

Fig. 2. Correlation between TN-C levels and sPAP.

$\pm 2.4 \mathrm{~mm}$ Hg; $\mathrm{p}<0.001$ on catheterization). The mitral valve area measured by the planimetric method on echocardiography showed a significant increase after PMBV $\left(1.1 \pm 0.1 \mathrm{~cm}^{2}\right.$ baseline, $1.8 \pm 0.2 \mathrm{~cm}^{2} 1$ month after PMBV, $\mathrm{p}<0.001)$. Using logistic regression analysis, the independent predictors of mitral stenosis were not associated with age, gender, diabetes mellitus, hypertension and smoking (table 3). However, TN-C was an independent predictor for mitral stenosis ( $\mathrm{p}=0.004$, OR: 2.31).

The difference in TN-C levels before and 1 month after PMBV is shown in figure 1 . The TN-C levels were significantly higher in patients with mitral stenosis before PMBV than after PMBV $(15.0 \pm 3.8 \mathrm{ng} / \mathrm{ml}$ at baseline and $10.9 \pm 3.1 \mathrm{ng} / \mathrm{ml}$ at 1 month after PMBV, $\mathrm{p}<0.001$ ).

TN-C levels were higher in patients with mitral stenosis before PMBV than in healthy subjects $(15.0 \pm 3.8$ and $9.4 \pm 2.9 \mathrm{ng} / \mathrm{ml} ; \mathrm{p}<0.001$, respectively). There was no significant difference between patients with mitral stenosis after PMBV and healthy subjects $(10.9 \pm 3.1$ and 9.4 $\pm 2.9 \mathrm{ng} / \mathrm{ml} ; \mathrm{p}=0.09$, respectively).

The correlation analysis of TN-C levels and sPAP is shown in figure 2 . In the Pearson correlation analysis, the 
levels of TN-C significantly positively correlated with sPAP measured by echocardiography $(\mathrm{r}=0.508, \mathrm{p}<$ 0.001 ). There was a significant negative correlation between $\mathrm{TN}-\mathrm{C}$ and mitral valve area. It is shown in figure $3(\mathrm{r}=-0.374, \mathrm{p}=0.001)$.

\section{Discussion}

In the present study we showed significantly increased levels of TN-C in patients with severe rheumatic mitral stenosis compared with a control group. However we evaluated the TN-C levels after successful PMBV and found decreasing levels of TN-C after PMBV. When we compared them with those of the control group, we did not find any significant difference. The TN-C levels were higher than those of the control group but there was no significance. We, therefore, believe that $\mathrm{TN}-\mathrm{C}$ levels are inversely related to mitral valve area. The increase in TN-C might reflect the severity of MS.

On the other hand, it was previously reported that $\mathrm{TN}-\mathrm{C}$ had an increase in pulmonary hypertension $[5,17]$. Smooth muscle cell proliferation is one of the pathophysiologic roles of TN-C in pulmonary hypertension $[8,9]$. The pathogenesis of pulmonary hypertension is multifactorial. High pulmonary resistance and high pulmonary artery pressure cause tissue remodeling in the pulmonary circulation, so these are key pathomechanisms of pulmonary hypertension. Pulmonary venous hypertension reflects elevated pulmonary capillary wedge pres- sure as a result of mitral or aortic valve diseases, left ventricular dysfunction, cardiomyopathy and pericardial disease [18]. Mitral stenosis is still the most common cause of pulmonary venous hypertension in developing countries. In the pathophysiology of pulmonary venous hypertension, dysfunction of the left heart causes an increase in pulmonary artery pressure due to the passive reflection of venous pressures into the arterial bed. Vascular remodeling can occur in all types of pulmonary hypertension. TN-C has a very important role in cardiopulmonary tissue remodeling by stimulating smooth muscle cell proliferation. Nevertheless, in the present study, the TN-C levels decreased like sPAP after successful PMBV compared to values before PMBV. There was also a positive correlation between TN-C levels and sPAP. It therefore seems that both $\mathrm{SPAP}$ and mitral valve area affect TN-C levels.

The limitation of the present study was the relatively small sample size, and thus the present findings should be confirmed by multicenter studies with larger sample sizes.

\section{Conclusions}

Higher TN-C levels were seen in patients with severe rheumatic mitral stenosis than in healthy subjects and $\mathrm{TN}-\mathrm{C}$ was an independent predictor for mitral stenosis. After successful PBMV, there was a dramatic decrease not only in sPAP levels but also in TN-C levels.

\section{References}

1 Bonow RO, Carabello BA, Chatterjee K, de Leon AC Jr, Faxon DP, Freed MD, Gaasch WH, Lytle BW, Nishimura RA, O'Gara PT, O'Rourke RA, Otto CM, Shah PM, Shanewise JS; 2006 Writing Committee Members; American College of Cardiology/American Heart Association Task Force: 2008 focused update incorporated into the ACC/AHA 2006 guidelines for the management of patients with valvular heart disease: a report of the American College of Cardiology/American Heart Association Task Force on Practice. Circulation 2008; 118:e523-e661.

-2 Nobuyoshi M, Arita T, Shirai S, Hamasaki N, Yokoi H, Iwabuchi M, Yasumoto H, Nosaka $\mathrm{H}$ : Percutaneous balloon mitral valvuloplasty: a review. Circulation 2009;119:211-219.
-3 Celik A: The relationship between tenascin$\mathrm{C}$ levels and the complexity of coronary lesion after myocardial infarction. J Atheroscler Thromb 2011;18:693-697.

- 4 Terasaki F, Okamoto H, Onishi K, Sato A, Shimomura H, Tsukada B, Imanaka-Yoshida K, Hiroe M, Yoshida T, Kitaura Y, et al: Higher serum tenascin-C levels reflect the severity of heart failure, left ventricular dysfunction and remodeling in patients with dilated cardiomyopathy. Circ J 2007;71:327-330.

5 Celik A, Kocyigit I, Calapkorur B, Korkmaz H, Doganay E, Elcik D, Ozdogru I: Tenascin$\mathrm{C}$ may be a predictor of acute pulmonary thromboembolism. J Atheroscler Thromb 2011;18:487-493.

6 Cowan KN, Jones PL, Rabinovitch M: Elastase and matrix metalloproteinase inhibitors induce regression, and tenascin- $\mathrm{C}$ antisense prevents progression, of vascular disease. J Clin Invest 2000;105:21-34.
7 Jones PL, Rabinovitch M: Tenascin-C is induced with progressive pulmonary vascular disease in rats and is functionally related to increased smooth muscle cell proliferation. Circ Res 1996;79:1131-1142.

8 Jones PL, Cowan KN, Rabinovitch M: Tenascin-C, proliferation and subendothelial fibronectin in progressive pulmonary vascular disease. Am J Pathol 1997;150:1349-1360.

-9 Jian B, Jones PL, Li Q, Mohler ER 3rd, Schoen FJ, Levy RJ: Matrix metalloproteinase-2 is associated with tenascin- $\mathrm{C}$ in calcific aortic stenosis. Am J Pathol 2001;159:321-327.

10 Jiang L, Wei XF, Yi DH, Xu P, Liu H, Chang Q, Yang SM, Li ZF, Gao HB, Hao GJ: Synergistic effects of cyclic strain and Th1-like cytokines on tenascin- $\mathrm{C}$ production by rheumatic aortic valve interstitial cells. Clin Exp Immunol 2009;155:216-223. 
11 Narin N, Kütükçüler N, Ozyürek R, Bakiler AR, Parlar A, Arcasoy M: Lymphocyte subsets and plasma IL-1 alpha, IL-2, and TNFalpha concentrations in acute rheumatic fever and chronic rheumatic heart disease. Clin Immunol Immunopathol 1995;77:172-176.

$\checkmark 12$ Morris K, Mohan C, Wahi PL, Anand IS, Ganguly NK: Enhancement of IL-1, IL-2 production and IL-2 receptor generation in patients with acute rheumatic fever and active rheumatic heart disease; a prospective study. Clin Exp Immunol 1993;91:429-436.

13 Polyakova V, Hein S, Kostin S, Ziegelhoeffer T, Schaper J: Matrix metalloproteinases and their tissue inhibitors in pressure-overloaded human myocardium during heart failure progression. J Am Coll Cardiol 2004;44: 1609-1618.
14 Tamaoki M, Imanaka-Yoshida K, Yokoyama K, Nishioka T, Inada H, Hiroe M, Sakakura $\mathrm{T}$, Yoshida T: Tenascin- $\mathrm{C}$ regulates recruitment of myofibroblasts during tissue repair after myocardial injury. Am J Pathol 2005; 167:71-80.

15 Lang RM, Bierig M, Devereux RB, Flachskampf FA, Foster E, Pellikka PA, Picard MH, Roman MJ, Seward J, Shanewise JS, et al: Recommendations for chamber quantification: a report from the American Society of Echocardiography's Guidelines and Standards Committee and the Chamber Quantification Writing Group, developed in conjunction with the European Association of Echocardiography, a branch of the European Society of Cardiology. J Am Soc Echocardiogr 2005;18:1440-1463.
16 Kircher BJ, Himelman RB, Schiller NB: Noninvasive assessment of right atrial pressure from inspiratory collapse of the inferior vena cava. Am J Cardiol 1990;66:493-496.

17 Schumann C, Lepper PM, Frank H, Schneiderbauer R, Wibmer T, Kropf C, Stoiber KM, Rüdiger S, Kruska L, Krahn T, et al: Circulating biomarkers of tissue remodelling in pulmonary hypertension. Biomarkers 2010;15: 523-532.

18 McGoon MD: Pulmonary hypertension; in Murphy JG, Lloyd MA (eds): Mayo Clinic Cardiology: Concise Textbook. Rochester, Mayo Clinic Scientific Press, 2007, pp $929-$ 950. 